\title{
Improving First Year Nursing Student's Test Scores through Pediatric Simulation
}

\author{
Jeanette Harris, Tamara Berghout, Pamela Anderson \\ School of Nursing, Weber State University, Ogden, UT, USA \\ Email: jeanetteharris@weber.edu, tamaraberghout@weber.edu, pammiller@weber.edu
}

Received 17 July 2015; accepted 18 August 2015; published 21 August 2015

Copyright (C 2015 by authors and Scientific Research Publishing Inc.

This work is licensed under the Creative Commons Attribution International License (CC BY). http://creativecommons.org/licenses/by/4.0/

(c) (i) Open Access

\section{Abstract}

Background: Student test scores in the pediatric portion were at a national percentile rank of 30, which was concerning. It was theorized that the main contributor to this dilemma was that the majority of students were not able to have a pediatric clinical experience. Objective: The purpose of this project was to determine if the addition of pediatric simulation scenarios would have an impact on student learning as evidenced by end of level test scores. Method: A convenience sample ( $n=100$ ) of first year nursing students attending a university in the western United States participated in this project. This was a mixed methods study. A quasi-experimental design was used to compare test scores of both a non-intervention group and an intervention group of students. A 5 point Likert scale questionnaire was also using post-intervention to assess for changes in perceptions of self-confidence. Results: After implementation of the pediatric focused scenarios, students' test scores increased to the 95th percentile. This 65 percentile increase is a significant change that suggests that pediatric simulation is effective in improving student exam performance. In addition, $\mathbf{8 1 \%}$ of students also reported perceptions of increased levels of self-confidence after implementation of simulation scenarios. Conclusion: The findings suggest that simulation is an effective way to create alternative pediatric clinical experiences which can, in turn, increase student comprehension, test scores, and self-confidence.

\section{Keywords}

Simulation, Simulation in Nursing Education, Nursing Education, Nursing Study \& Teaching, Experiential Learning, Simulation in Nursing Practice, Pediatric Simulation

\section{Introduction}

When educating future nurses, finding sufficient clinical opportunities can be problematic, especially when looking for specific patient populations. Pediatric clinical opportunities in particular can be difficult to obtain for 
students, especially in some locations. Simulation implementation is one answer to the question of how to ensure that nursing students are exposed to the pediatric patient population when limited clinical options are available. According to Jeffries [1], the recent move toward integrating simulation into nursing curricula, either as a clinical enhancement, substitute, or adjunct, is occurring due to several factors: a) the increased need for clinical sites and instructors as more schools of nursing are established; b) an increasing nurse educator shortage calls for schools and universities to seek innovative approaches to traditional nursing education; and c) concerns about patient safety.

Simulation has become a valued educational strategy in the field of nursing. The 2011 Institute of Medicine's Report on the Future of Nursing indicated that the use of simulation to educate future nurses was essential [2]. In addition, the National League for Nursing states: "Simulation is valued for its ability to provide realistic, context-rich experiential learning in a safe environment [3].”

With this encouragement, a plan was implemented to use simulation as a strategy to increase student exposure to the pediatric population and hopefully bridge the gap in their understanding of how the pediatric patient fits into medical and surgical concepts taught in the classroom. This paper outlines the process the school of nursing used to implement a plan to integrate multiple pediatric simulation scenarios into an existing curriculum and the results of the implementation on student comprehension.

\section{Background}

Our motivation for this project began with an alarmingly low student performance on the end of level pediatric test. This dilemma was felt to be the result of a combination of factors. The greatest identified contributing factor was believed to be a lack of pediatric clinical experience for students because of limited opportunities in local pediatric clinics.

Limited clinical options, coupled with extreme seasonal variations in pediatric census resulted in little to no pediatric clinical experiences for nearly all of the nursing students. Since the majority of students did not have the opportunity to take part in a pediatric clinical experience, the need to supplement with an alternative clinical experience was paramount. Pediatric simulation was therefore identified as a strategy that could be utilized to increase pediatric-specific comprehension and student confidence in first year nursing students.

Simulation is a fascinating educational method for delivering nursing-specific knowledge. Simulation has also been identified as an effective way to provide the learner with clinical opportunities that might otherwise be missed. A study published in 2012 [4] demonstrated that up to 25\% of total clinical time could successfully be replaced with simulation.

Using simulation in nursing education to improve student skills has become a common practice and numerous studies have demonstrated that quality simulation can be an effective teaching method. According to Berndt [5], the goal of simulation use is to help students to experience real life scenarios in the safety of the educational environment. Studies have demonstrated that the use of simulation can increase patient safety outcomes [6] [7]. Research has likewise demonstrated that simulation can improve technical skills, [8] [9] assist in the development of critical thinking, [10] and enhance teamwork among nursing students [11]-[13].

Therefore, a plan was established to create multiple simulated scenarios. Each scenario was designed to focus on a distinct pediatric-specific concept. The scenarios would be implemented into existing curriculum with the objective of augmenting student learning. The primary intent of this study was to evaluate whether the introduction of multiple simulation pediatric scenarios would have a positive impact on student pediatric specific nursing knowledge as measured by end of level test scores. The other purpose of this study was to determine the impact the scenarios had on student self-confidence as measured by the NLN Student Satisfaction and Self-Confidence in Learning Scale, (SSSCLS).

\section{Methods}

Low scores in the pediatric exam stimulated the need for an intervention. The exam demonstrating the low scores was the RN Nursing Care of Children 2007 form B [14] exam from Assessment Technologies Institute (ATI) [14]. ATI is a commercial testing product company. A quasi-experimental, posttest design was used to determine if adding simulation scenarios would have an effect on students' end of level test scores. A convenience sample was utilized, consisting of all students enrolled in the first year Medical-Surgical course. All students enrolled in the academic year were included in the study. 100 students from two related campuses partici- 
pated in the four added simulation scenarios. The PN Nursing Care of Children Exam 2008 form B from ATI [14] was the assessment tool used to measure effectiveness of the intervention. This selected test was given at the end of their first year of nursing to bench mark the student's competency in pediatric nursing.

To meet our goal, a team of nurse educators and pediatric nurse specialists was created. Following an examination of questions most frequently missed and a process of team deliberation, the most relevant pediatric specific concepts were identified. At this point, key technical skills were also identified for each of the four concepts. Finally, essential assessment skills were identified to incorporate within each scenario. Specific scenarios were then created by the team; each scenario was reviewed and refined until the team members were satisfied with the quality of the four scenarios in meeting our identified outcomes.

Each of the four scenarios outlined a different pediatric concept. The concepts identified as most important included the following: diabetic ketoacidosis, tonsil and adenoidectomies with respiratory problems, pediatric developmental assessment, and ventricular septal defects. Each of the four scenarios was designed to be completed during a two hour time slot. Students were divided into pairs and worked as a team for each scenario.

The goal was to ensure that each student had the most realistic patient care experience possible. The students were required to attend an eight hour pediatric simulation day. Each student was required to act as the nurse caring for the pediatric patient and was systematically rotated through each of the four scenarios. For each patient, there was a requirement to use nursing assessment skill performance for multiple stages of each conditions severity, along with multiple technical skill performance requirements. Family interactions were also incorporated into the scenarios. The students had a pre-simulation orientation and a post-session debriefing.

In addition, to the ATI end of level test, a student questionnaire assessing student perceptions of effectiveness was administered to students at the conclusion of the simulation day by an unbiased party. The Student Satisfaction and Self-Confidence in Learning Scale, (SSSCLS) which has been developed in 2007 by the National League for Nursing is a tool which required a response from strongly agree to strongly disagree [15]. Student participation in the survey was anonymous and optional. Four of the questions have been used in this study.

IRB approval and informed consent was obtained and no student identifiers were used in the data analysis of this study. Data to measure comprehension was collected from the ATI [14] test bank. Data from the SSSCLS [15] questionnaire was collected and entered into a data base for analysis. The researchers obtained the results after all of the students had an opportunity to complete the questionnaire. Thirteen students chose not to participate in the nursing student satisfaction with pediatric simulation experience survey.

\section{Results}

The purpose of this study was to explore the effect of the addition of four 2 hour pediatric simulation scenarios on student comprehension and perceptions of self-confidence. The participants in this study were 100 first year, second semester Associate Degree nursing students attending one of the two campuses within the same nursing program. Participant's age ranged from 20 to 51 and were $88 \%$ female and $12 \%$ were male.

Participants in this study were not randomly assigned, since all students in the program were included in the study. The comparison group consisted of the previous year's group of 100 equivalent students enrolled in the same nursing program.

Test scores from both the comparison group and the intervention group were separately calculated to reflect the national percentile rank. The mean score for the comparison group percentile was 30 (SD = 9.8). The intervention group mean percentile was $95(\mathrm{SD}=5.42)$. This demonstrates a statistically significant percentile difference of 65 .

In measuring student perceptions of effectiveness of the simulation intervention, the result was also statistically significant. $81 \%$ of the students strongly agreed or agreed that that the simulation experience was helping them to develop the skills and obtain the knowledge necessary to perform confidently in clinical situations. The four questions applicable to this paper are seen in Figure 1.

\section{Conclusions}

A limitation to this study was that the comparison and the intervention groups were different cohorts of students. The first group took the ATI RN Nursing Care of Children test as assigned in the curriculum. Once the problem was identified and the intervention was designed, the intervention cohort was assigned to take the ATI PN Nursing Care of Children Test. The population was also a convenience sample; randomization of the sample 


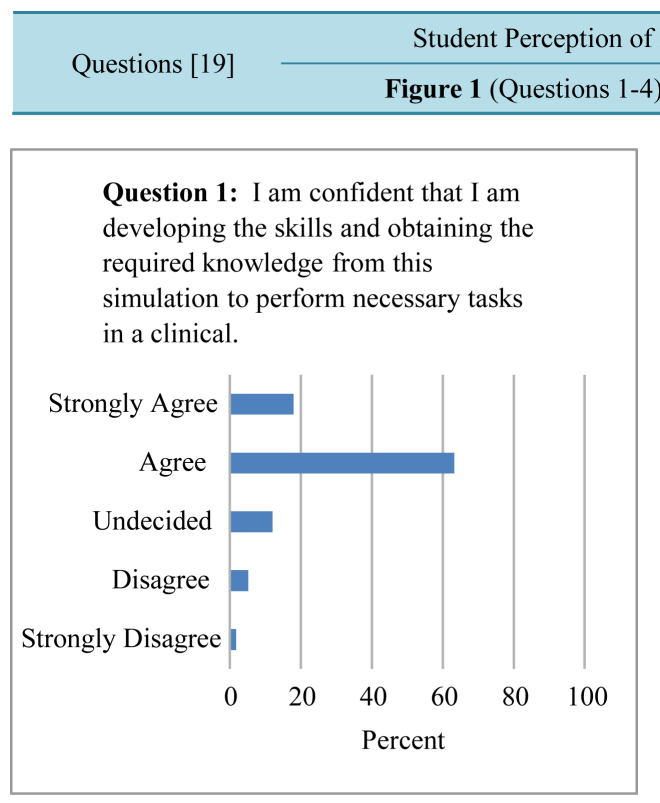

Student Perception of Effectiveness of Simulation Intervention

Figure 1 (Questions 1-4)
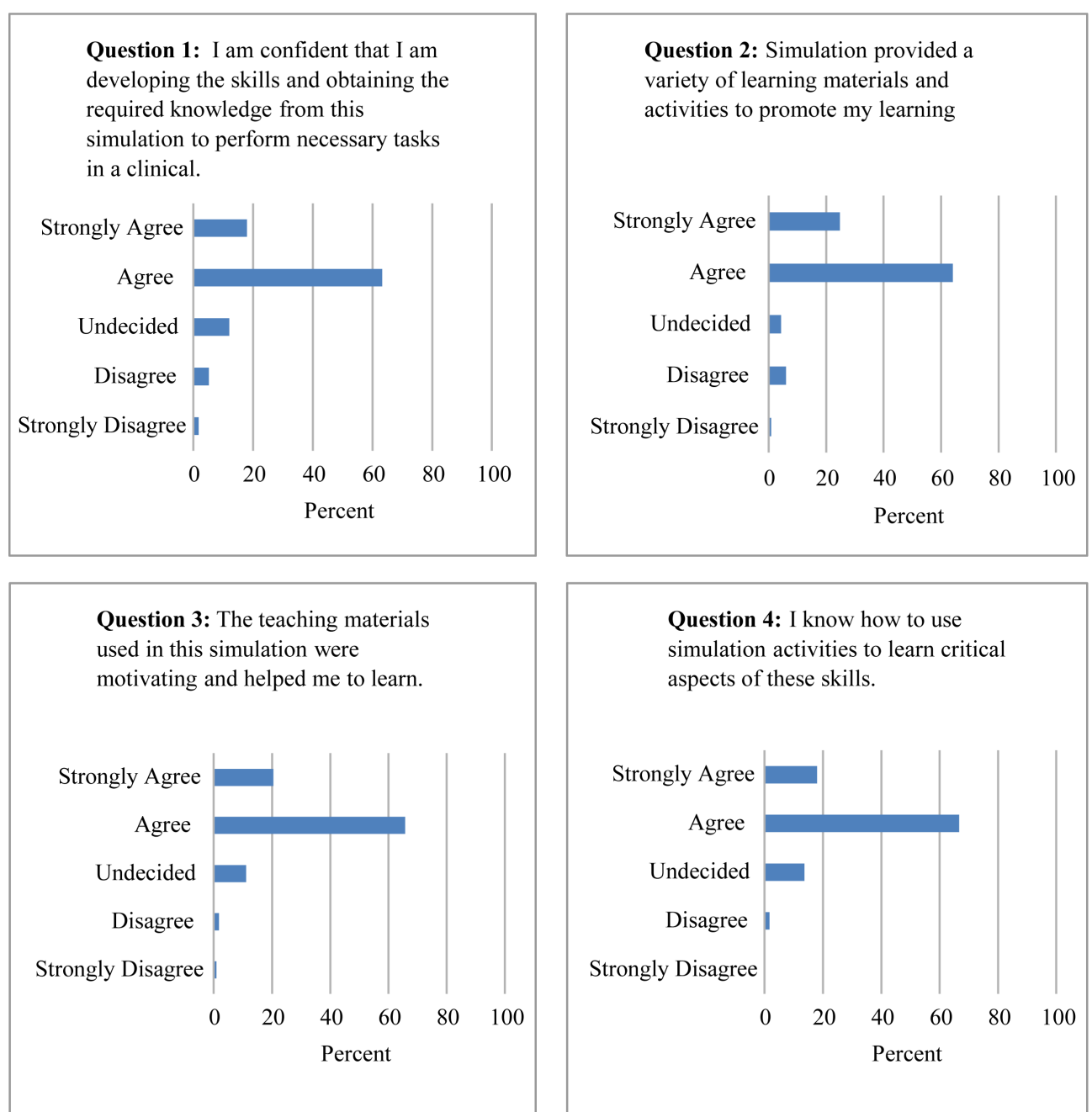

Question 3: The teaching materials used in this simulation were motivating and helped me to learn.

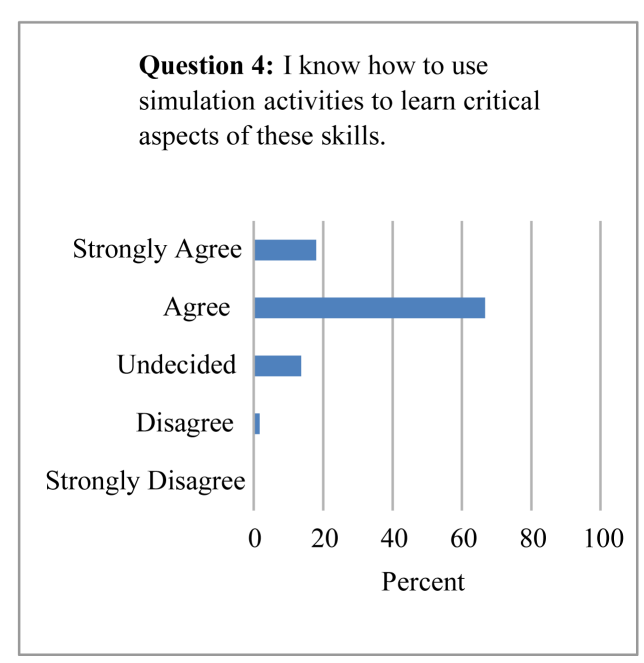

Figure 1. Questions with student post-intervention perceptions.

would have added strength to the findings. Despite these limitations, the effect was significant and suggested that simulation could increase student comprehension.

The post simulation student survey [15] results suggested that students had higher confidence in their skills after simulation experiences. This conclusion confirmed previous studies [16] where students also reported a rise in confidence after implementing simulation.

Our findings from test results demonstrate that student comprehension can be increased with the well-planned use of simulation.

Our results also reinforce past findings [17] which suggest that carefully planned simulation experiences, when aligned with course content and outcomes, can be a successful alternate to clinical time. These findings are important for nurse educators who are struggling with the dilemma of poor comprehension and insufficient clinical placement opportunities.

\section{Acknowledgements}

The authors are grateful to and thank all who assisted with this project, especially Kathy Culliton, MS, APRN, Jill Daly, EdD(c), MSN, RN, and a special thank you to our partner Cynthia Candland, MSN, RN, who passed 
away during the writing of this paper.

\section{References}

[1] Jeffries, P. (2008) Getting in S.T.E.P. with Simulations: Simulations Take Educator Preparation. Nursing Education Perspectives, 29, 70-73. http://search.ebscohost.com.hal.weber.edu:2200/login.aspx?direct=true\&db=cmh\&AN=31618508\&site=chc-live

[2] The Institute of Medicine (2011) Report on the Future of Nursing: Focus on Education. http://www.iom.edu/Reports/2010/The-Future-of-Nursing-Leading-Change-Advancing-Health/Report-Brief-Education .aspx?page=2

[3] National League for Nursing (2015). http://www.nln.org/professional-development-programs/simulation

[4] Watson, K., Wright, A., Morris, N., McMeeken, J., Rivett, D., Blackstock, F., Jones, A., Haines, T., O’Connor, V., Watson, G., Peterson, R. and Jull, G. (2012) Can Simulation Replace Part of Clinical Time? Two Parallel Randomized Controlled Trials. Medical Education, 46, 657-667. http://dx.doi.org/10.1111/j.1365-2923.2012.04295.x

[5] Berndt, J. (2014) Patient Safety and Simulation in Prelicensure Nursing Education: An Integrative Review. Teaching and Learning in Nursing, 9, 16-22. http://dx.doi.org/10.1016/j.teln.2013.09.001

[6] Ironside, P.M., Jeffries, P.R. and Martin, A. (2009) Fostering Patient Safety Competencies Using Multiple Patient Simulation Experiences. Nursing Outlook, 57, 332-337. http://dx.doi.org/10.1016/j.outlook.2009.07.010

[7] Ballangrud, R., HLL-Lord, M.L., Persenius, M. and Hedelin, B. (2014) Intensive Care Nurses’ Perceptions of Simulation-Based Team Training for Building Patient Safety in Intensive Care: A Descriptive Qualitative Study. Intensive and Critical Care Nursing, 30, 179-187. http://dx.doi.org/10.1016/j.iccn.2014.03.002

[8] Broussard, L., Myers, R. and Lemoine, J. (2009) Preparing Pediatric Nurses: The Role of Simulation-Based Learning. Issues in Comprehensive Pediatric Nursing, 32, 4-15. http://dx.doi.org/10.1080/01460860802610178

[9] Vincent, M.A., Sheriff, S. and Mellott, S. (2015) The Efficacy of High-Fidelity Simulation on Psychomotor Clinical Performance Improvement of Undergraduate Nursing Students. CIN: Computers, Informatics, Nursing, 33, 78-84. http://dx.doi.org/10.1097/CIN.0000000000000136

[10] Goodstone, L., Goodstone, M.S., Cino, K., Glaser, C.A., Kupferman, K. and Dember-Neal, T. (2013) Effect of Simulation on the Development of Critical Thinking in Associate Degree Nursing Students. Nursing Education Perspectives, 34, 159-162. http://dx.doi.org/10.5480/1536-5026-34.3.159

[11] Bultas, M., Hassler, M., Ercole, P. and Rea, G. (2014) Effectiveness of High-Fidelity Simulation For Pediatric Staff Nurse Education. Pediatric Nursing, 40, 27-42, Professional Development Collection, EBSCOhost, Viewed 19 June 2015.

[12] Decker, S., Sportsman, S., Puetz, L. and Billings, L. (2008) The Evolution of Simulation and Its Contribution to Competency. Journal of Continuing Education in Nursing, 39, 74-80. http://dx.doi.org/10.3928/00220124-20080201-06

[13] Lewis, D.Y. and Ciak, A.D. (2011) The Impact of Simulation Lab Experience for Nursing Students. Nursing Education Perspectives, 32, 256-258. http://dx.doi.org/10.5480/1536-5026-32.4.256

[14] The Pediatric Comprehensive Exam (2015) Assessment Technologies Institute. https://www.atitesting.com/About.aspx

[15] National League for Nursing (2007) Learner Satisfaction and Self-Confidence in Learning: The Student Satisfaction and Self-Confidence in Learning Scale (SSSCLS) Used with Permission Copyright 2005 National League for Nursing, Reprinted with Permission.

[16] Pauly-O’Neill, S., Prion, S. and Nguyen, H. (2013) Comparison of Quality and Safety Education for Nurses (QSEN)Related Student Experiences during Pediatric Clinical and Simulation Rotations. Journal of Nurse Education, 52, 534538. http://dx.doi.org/10.3928/01484834-20130819-02

[17] Henneman, E.A., Cunningham, H., Roche, J.P. and Curnin, M.E. (2007) Human Patient Simulation: Teaching Students to Provide Safe Care. Nursing Education, 32, 212-217. http://dx.doi.org/10.1097/01.NNE.0000289379.83512.fc 